\title{
ANÁLISE TÊMPORO ESPACIAL E REGIME DAS CHUVAS NA REGIÃO DAS MISSÕES, ESTADO DO RIO GRANDE DO SUL, BRASIL
}

\author{
RIBEIRO, Arnaldo de Araujo - ribeirogeo@yahoo.com.br \\ Programa de Pós-Graduação em Geografia; Universidade Federal de Santa \\ Catarina, UFSC \\ ZAVATTINI, João Afonso - jazavattini@hotmail.com \\ Programa de Pós-Graduação em Geografia; IGCE - Universidade Estadual \\ Paulista - Unesp Campus de Rio Claro, SP
}

\begin{abstract}
RESUMO: A análise da chuva na Região Missões-RS feita por Ribeiro, (2012), confirmou a hipótese de que a Região se caracteriza pela variabilidade de episódios chuvosos e de estiagens. Neste artigo, o objetivo é apresentar os resultados da análise têmporo espacial e do regime das chuvas na área de estudo. Assim, a análise climática é vista a partir dos dados anuais, sazonais e mensais. Para isso procedeu-se a organização dos dados e o software Surfer 8 possibilitou a visualização da chuva através de cartogramas de isoietas, painéis têmporo espaciais e pluviogramas. Constatou-se que a Região, tanto se destaca nos anos secos e chuvosos perante o entorno, constituindo-se como área seguidamente atingida por extremos no volume acumulado e distribuição da chuva.
\end{abstract}

Palavras- chaves: distribuição, chuvas, estiagens, Região Missões-RS

ANALYSIS TIME SPATIAL AND REGIME OF RAINFALL IN THE REGION OF MISSIONS, STATE OF RIO GRANDE DO SUL, BRAZIL

ABSTRACT: The rain analysis in the Missões area, RS done by Ribeiro, (2012), confirmed the hypothesis of that area is known by the variability of many rainy and drought moments. In this article, the main objective is to present the results from the analysis of the rain time spatial and the regime in this area. So, the climate analysis is noticed by anual, seasonal and monthly data. For this, an organization of data was proceeded and using the Surfer 8 software that was possible to see the rain through isohyets cartograms, time spatial panels and pluviograms. It was stated in that area, the dry years as much as the rainy ones, both emphasizes towards the enclousing area, being an area that is constantly hit by huge volume of rain and the rainfall distribution.

Keywords: distribution, rain, drought, Missões area RS

\section{INTRODUÇÃO, JUSTIFICATIVAS E OBJETIVOS DO ESTUDO DA CHUVA NA REGIÃO DAS MISSÕES}

A importância do estudo do clima está relacionada ao fato de ser um dos componentes mais importantes do ambiente natural, participando dos processos geomorfológicos e de formação de solos, do crescimento e desenvolvimento de plantas e influenciando diretamente nas atividades humanas, principalmente quando se é afetado por variações significativas de seus elementos.

Ao se trabalhar a variabilidade temporal e espacial das chuvas na Região das Missões, permeia-se a temática da variabilidade climática, pelo fato de se tratar da variação em volume e períodos de chuva ou estiagens em determinada área. Assim, em meio à variabilidade climática, segundo Britto et. al. (2006), um dos principais fenômenos físicos é justamente a variabilidade da precipitação 
pluvial, que é uma das variáveis climáticas que maior influência exerce na qualidade do meio ambiente.

A Região das Missões foi alvo de análise climática detalhada, com base nos princípios da abordagem dinâmica no que compete a distribuição da chuva. Para tanto, apoiou-se teoricamente no conceito de Sorre (1951) para clima e no paradigma de Monteiro (1971), fundamentais para análise dos elementos climáticos.

A análise das chuvas e estiagens na Região das Missões-RS se mostrou imprescindível em estudo apresentado por Ribeiro, (2012), o qual confirmou a hipótese de que a região se caracteriza pela variabilidade de episódios chuvosos e de estiagens revelados pela análise geográfica do clima, bem como sustentados pela abordagem da Percepção Climática dos moradores locais.

Neste artigo, o objetivo é apresentar os resultados da análise têmporo espacial e o regime das chuvas na área de estudo, sendo que, ambos contribuíram para os resultados da pesquisa acima referida. A abordagem teórico-metodológica para a análise da distribuição das chuvas segue os preceitos da Climatologia Geográfica de Monteiro (1971) e Zavattini (2004). Sendo assim, o estudo climático das chuvas na área de estudo é visto a partir dos dados anuais, sazonais e mensais.

\section{MATERIAL E MÉTODOS APLICADOS À ANÁLISE DA CHUVA}

Elegeu-se a Região das Missões, situada na Mesorregião Noroeste do estado do Rio Grande do Sul, Brasil para a análise da chuva e estiagens. Os resultados foram obtidos a partir da coleta dos dados mensais de chuva do período de 1992 a 2010 de quatro postos meteorológicos, que recobrem a região, sendo um posto localizado no centro da região, no município de São Luiz Gonzaga, este pertencente ao Instituto Nacional de Meteorologia (INMET), e outros três localizados imediatamente nas bordas externas da região, nos municípios de São Borja, Santa Rosa e Ijuí, os quais estão sob a responsabilidade da Fundação Estadual de Pesquisas Agropecuárias (FEPAGRO). A área compreendida pelo estudo e a localização dos postos meteorológicos é vista no mapa da Figura 1. Com a obtenção de dados meteorológicos desses quatro postos oficiais se possibilitou visualizar a variação têmporo espacial e o regime mensal da chuva na área.

A análise climatológica teve início elegendo-se o arco de tempo de 19 anos comum para as quatro localidades e que compôs o período de 1992 a 2010. Observa-se que os dados de chuva fornecidos pelo INMET para São Luiz continham falhas nos primeiros oito meses do ano de 2001, onde por conveniência e caráter estratégico deste posto meteorológico optou-se por incluí-lo mesmo assim, preenchendo as falhas com os dados das últimas Normais Meteorológicas (mensal e anual) dos anos de 1961-1990 fornecidas pelo INMET (2009).

A partir dos dados mensais, procedeu-se a organização e o tratamento dos mesmos como base de dados para a confecção de cartogramas de isoietas na escala anual e painéis têmporo espaciais na escala anual, sazonal e mensal por meio do software Surfer 8 a partir de pontos de coleta de dados com 
localização aleatória o que permitiu a interpolação das variáveis e sua extrapolação para a área a partir de uma resolução espacial em metros.

Este recurso possibilitou a representação das chuvas dos 19 anos para as quatro localidades na forma de painéis, demonstrando a sua variação no tempo e no espaço em análise. Os intervalos de classe que definiram a variação do volume de chuva que se apresentaram do padrão seco ao mais chuvoso, foram calculados pela técnica estatística de Sturges, conforme Gerardi (1981) e assim foi possível a representação da precipitação anual, sazonal e mensal.

Outro recurso metodologicamente aplicado para o estudo das chuvas na escala mensal foi à confecção de pluviogramas para as quatro localidades. Os referidos pluviogramas foram baseados em Schröder (1956) e organizados de forma a mostrar a variação porcentual das chuvas entre os meses do ano, possibilitando a visualização através de intervalos de classes estabelecidos estatisticamente pela fórmula de Sturges, conforme Gerardi (op. cit.), o que resultou, para o conjunto de dados, em 11 classes com intervalos de 3,2\%, que indicaram os meses menos chuvosos até os mais chuvosos dentro do período.

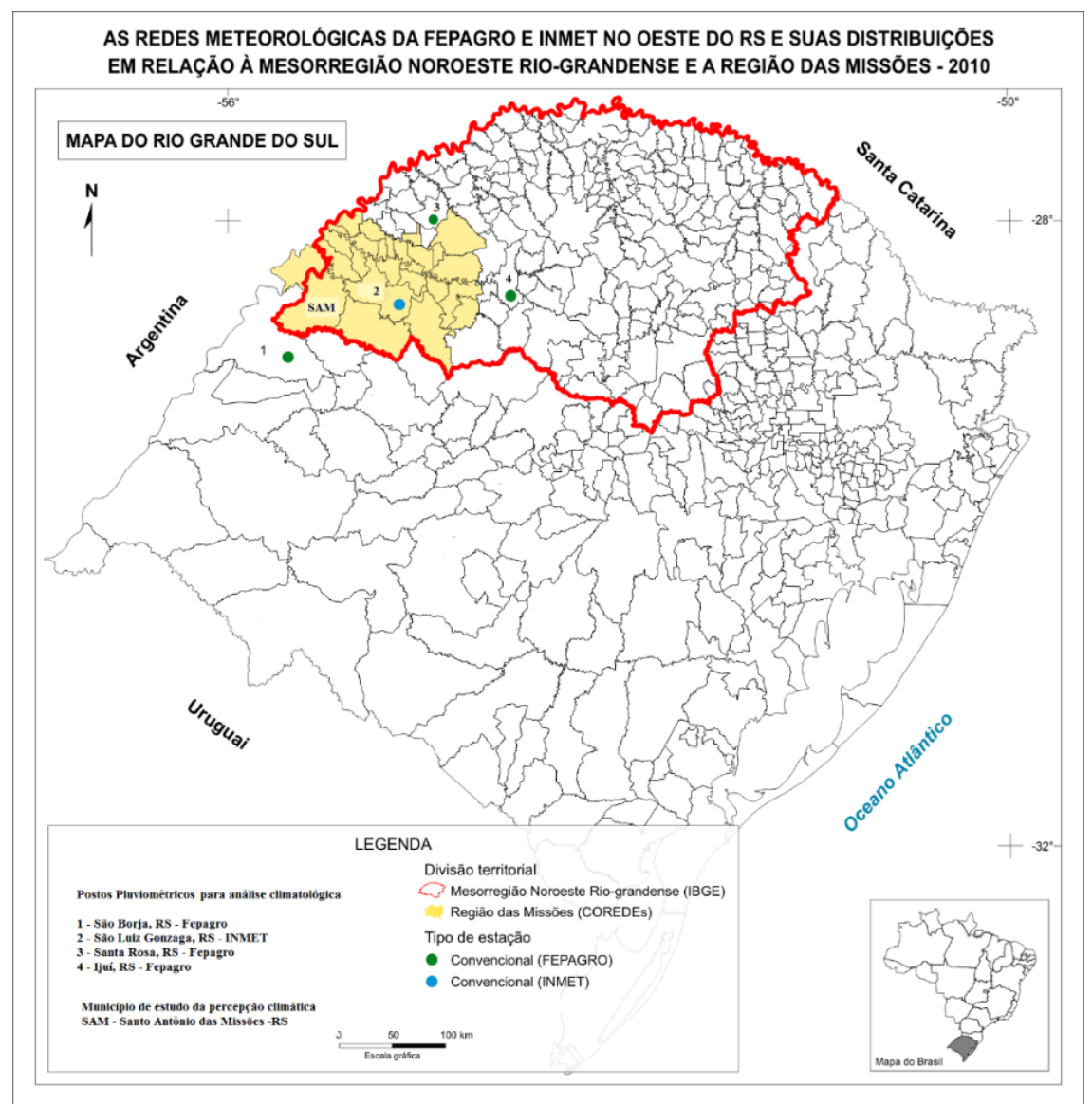

Figura 1 - Mapa de localização da Mesorregião Noroeste e Missões em relação à rede meteorológica da FEPAGRO e INMET. Organização: Ribeiro, 2016. 


\section{RESULTADOS E DISCUSSÕES}

\subsection{ANÁlISE DA CHUVA NO PERÍODO DE 1992-2010 NA REGIÃO DAS MISSÕES, ESPACIALIZAÇÃO DA PRECIPITAÇÃO ANUAL A PARTIR DE CARTOGRAMAS DE ISOIETAS}

Tomando-se como parâmetro para a análise dos cartogramas da Figura 2 e o painel têmporo espacial anual Figura 3, os intervalos de classes utilizados para representar a variação anual das chuvas foram submetidos à análise de frequência para o período, e das sete classes sugeridas pela técnica de Sturges (GERARDI, op. cit), três delas representam os mais repetidos: os intervalos que variam de 1492.1 a $1743.4 \mathrm{~mm}$, de 1743.5 a $1994.8 \mathrm{~mm}$ e de 1994.9 a 2246.2 mm conforme mostra o Quadro 1 representados nos três tons de verde. Salienta-se que os Quadros 1, 2 e 3 não objetivam uma discussão, mas sim, apenas mostrar os intervalos de classes estabelecidos, os quais subsidiarão a análise dos cartogramas e dos painéis têmporo espaciais.

Quadro 1 - Frequência de distribuição do volume de chuva anual conforme Sturges para definição de classes representativas de menos chuvoso, habitual e mais chuvoso para a área de estudo, entre os anos de 1992 a 2010. Organização: RIBEIRO, A. de. A. 2016

\begin{tabular}{|c|c|c|c|c|c|c|}
\hline & \multicolumn{4}{|c|}{ Postos Pluviométricos } & \multirow[b]{2}{*}{ FA/ FR } & \multirow[b]{2}{*}{ Representação } \\
\hline $\begin{array}{c}\text { Intervalos } \\
(\mathrm{mm})\end{array}$ & P1 & P2 & P3 & P4 & & \\
\hline $989,3-1240,6$ & 2 & 1 & 1 & 1 & $5 / 6,5 \%$ & Seco \\
\hline $1240,7-1492$ & 2 & 1 & 4 & 3 & $10 / 13,1 \%$ & \\
\hline $1492,1-1743,4$ & 9 & 2 & 4 & 4 & $19 / 25 \%$ & Esperado/Habitual \\
\hline $1443,5-1994,8$ & 5 & 5 & 6 & 5 & $21 / 27,6 \%$ & Esperado/Habitual \\
\hline $1994,9-2246,2$ & - & 6 & 3 & 5 & $14 / 18,4 \%$ & Esperado/Habitual \\
\hline $2246,3-2497,6$ & - & 2 & 1 & 1 & $4 / 5,3 \%$ & Chuvoso \\
\hline $2497,7-2749$ & 1 & 2 & - & - & $2 / 2,6 \%$ & Mais Chuvoso \\
\hline Anos & 19 & 19 & 19 & 19 & $76 / 100 \%$ & \\
\hline
\end{tabular}

Nos anos de 1992, 1993 e 1994, Figura 2, as isoietas apresentam variação considerada dentro do esperado. Já em 1995 refletem uma situação diferente da observada anteriormente, pois as chuvas ficaram abaixo do normal. No conjunto dos cartogramas da Figura 2, 1995 e 2004 foram os anos menos chuvosos. Em anos com baixo acumulado de chuva, como em 1995, São Borja, no oeste, destaca-se como a área menos chuvosa com totais próximos aos $989.3 \mathrm{~mm}$.

O cartograma de 1997 demonstra chuvas anuais acima do normal, principalmente na porção central da Região, São Luiz Gonzaga com 2497.7 mm. Este ano mais chuvoso que os anteriores na região missioneira, representada por São Luiz Gonzaga, no centro, é referência dos extremos relacionados à chuva. O centro da região se destaca tanto nos anos mais chuvosos com o máximo acumulado, e nos anos menos chuvosos. O cartograma de 1998 destaca-se ao ser comparado com o de 1997, e aparece entre os anos mais chuvosos cujo total acumulado anual atinge picos máximos, próximo a 2749 mm, em São Luiz Gonzaga. Neste ano chuvoso, São Luiz Gonzaga destacou-se com o máximo de chuva, o que sustenta a tendência de ser o "core" da região ser referência em volumes máximos e mínimos no acumulado anual em anos mais e menos chuvosos. Em 1999 os totais de chuva se reduzem bastante em 
relação a 1998, pois o total acumulado ficou abaixo do habitual. No ano de 2000 retorna à distribuição habitual, e em 2001 o acumulado se reduz.

Já em 2002 às isoietas revelam ser este, o ano mais chuvoso da série temporal. Diferentemente do ano de 1998, que também foi considerado com chuvas acima do esperado em parte da área analisada, 2002 se destaca por ser de chuvas acima do normal em todas as localidades. Os picos máximos foram registrados em São Luiz Gonzaga e São Borja, setor centro-oeste da área, em São Luiz Gonzaga o acumulado ficou em $2748.7 \mathrm{~mm}$, já o setor nordeste, que envolve Santa Rosa e Ijuí, a chuva também foi acima do habitual, mas com acumulados inferiores aos das duas localidades anteriormente referidas. Ou seja, São Luiz Gonzaga e São Borja destacam-se, não só por registrar os menores índices de chuva em anos menos chuvosos, como também por registrarem os índices anuais mais elevados de chuva em anos chuvosos.

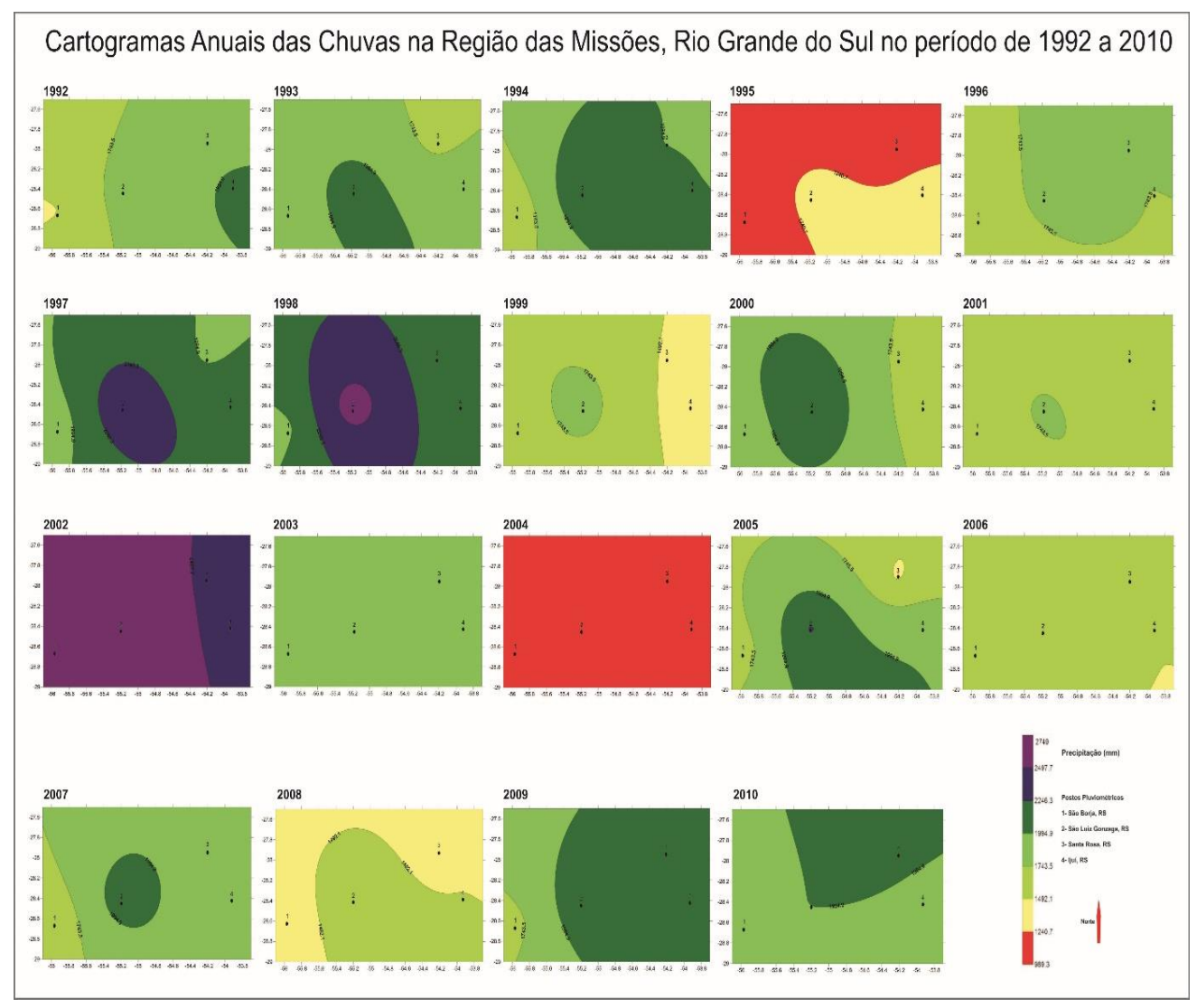

Figura 2 - Cartogramas Anuais das Chuvas em milímetros $(\mathrm{mm})$ na Região das Missões, Rio Grande do Sul no período de 1992 a 2010. Fonte: Banco de Dados Meteorológicos; BDMET/INMET. Organização: RIBEIRO, A. de. A. 2016.

Em 2003, após um ano de índices elevados, os mesmos retornam a habitualidade. O total anual foi bem distribuído, mas apresentou redução do volume em relação do ano anterior revelando o transcurso para o ano de 2004, que aparece como o ano menos chuvoso da série temporal com variação de 989.3 a $1240.7 \mathrm{~mm}$. 
São Borja registrou o mínimo acumulado, ficando com $989.3 \mathrm{~mm}$, seguido de São Luiz Gonzaga com 1122.9 mm, Santa Rosa com 1141.8 mm e Ijuí com $1163.3 \mathrm{~mm}$. Ou seja, o ano foi o menos chuvoso figurando em São Borja e São Luiz Gonzaga os menores índices de chuva. Estas duas localidades também foram referência no ano mais chuvoso como as que tiveram os maiores acumulados.

Na sequência, o ano de 2005, 2006 e 2007 apresentam-se com chuvas dentro do esperado, já em 2008, as isoietas demonstram chuvas abaixo do esperado em parte da região, revelando a alternância de anos ora menos ora mais chuvosos. Em 2009 retorna a distribuição das chuvas dentro dos valores normais e o último ano da série temporal apresentou volume de chuva habitual, porém com valores superiores aos últimos sete anos quando se observa a distribuição na Região como um todo.

\subsection{DISTRIBUIÇÃO TÊMPORO ESPACIAL DA PRECIPITAÇÃO ANUAL}

Seguindo uma visão geral, da Figura 3, evidencia-se a variação anual das chuvas entre 989,3 a 2748,7 mm, assim evidencia-se períodos de excesso e deficit de chuva, fato que condiz com a necessidade de estudos sobre a variação do volume das chuvas. Como é de conhecimento, o estado do Rio Grande do Sul registra habitualmente volumes de chuvas elevados e bem distribuídos ao longo do ano, salvo períodos de estiagens ocasionais. Conforme o Quadro 1 e a Figura 3 , os valores que correspondem ao habitual para as Missões, variam de 1492,1 a $2246,3 \mathrm{~mm}$ e que são vistos no painel, a baixo sob os tons de verde.

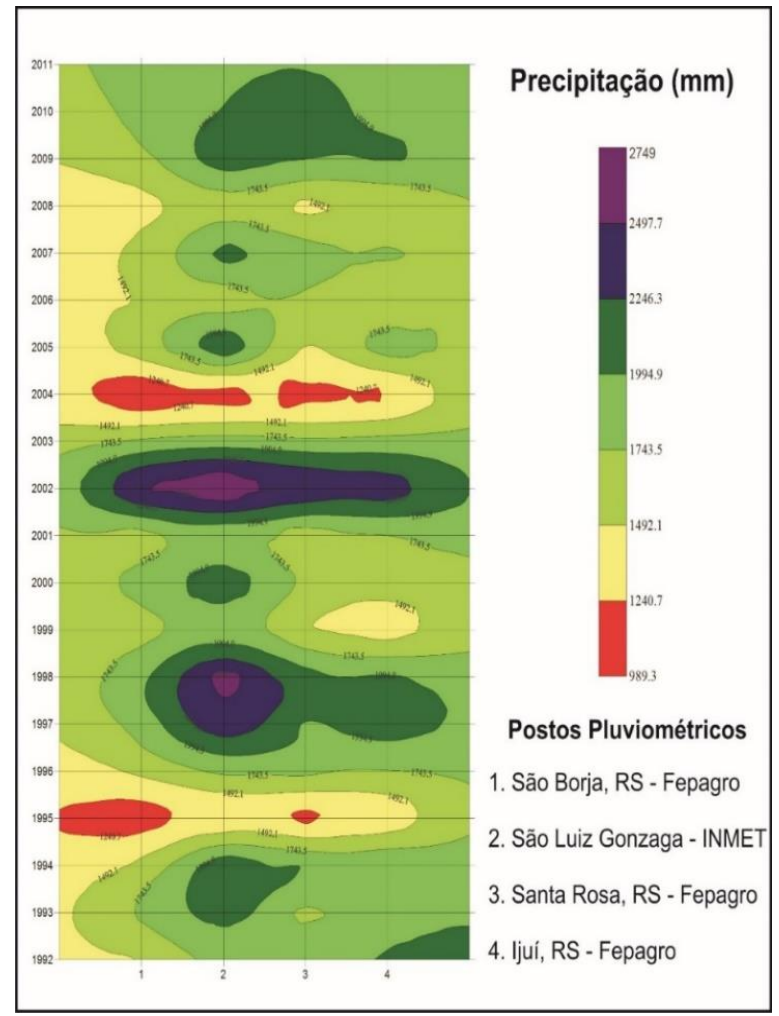

Figura 3 - Painel têmporo espacial anual das chuvas na Região das Missões; Período 1992-2010. Organização: RIBEIRO, A. de. A. 2016. 
A variação anual da precipitação indica que os anos que apresentaram volumes de chuva menores foram 1995 e 2004. O ano de 2004 configurou-se como o mais seco nas quatro localidades: São Borja, a oeste da região, com 989,3 mm e São Luiz Gonzaga no centro-oeste com 1122,9 mm, configurandose como os menores valores acumulados para 2004; Santa Rosa localizada ao norte e Ijuí a leste da região também tiveram acumulados baixos. Assim, o nordeste da região, mesmo em anos mais secos, registrou volumes maiores de chuva do que o setor mais oeste. A partir desta constatação infere-se um padrão de variação menor no sentido leste - oeste em anos menos chuvosos, ou seja, pode-se dizer que as chuvas quanto mais a oeste menores são em volume nos anos mais secos.

Os anos de 1997, 1998 e 2002, com totais acima de 2246,3 mm, foram os três mais chuvosos em São Luiz Gonzaga assim como em São Borja. São Luiz Gonzaga situa-se praticamente no centro da região, o que pode vir a comprovar que o cerne das Missões é passível de sofrer ciclicamente variações significativas no volume chuva, com anos secos seguido de anos chuvosos, pois se apresenta tanto como referência para os mínimos acumulados em anos menos chuvosos, como para os máximos em anos chuvosos.

\subsection{DISTRIBUIÇÃO TÊMPORO ESPACIAL DA PRECIPITAÇÃO SAZONAL}

Para a análise sazonal das chuvas, primeiramente observa-se que, as estações do ano foram divididas conforme o calendário civil. Os valores que correspondem ao habitual para a região variam entre 228 a 613,8 mm Quadro 2.

Quadro 2 - Frequência de distribuição do volume de chuva sazonal conforme Sturges para definição de classes representativas de menos chuvoso, habitual e mais chuvoso para a área entre os anos de 1992 a 2010. Organização: RIBEIRO, A. de. A. 2016

\begin{tabular}{|c|c|c|c|c|c|c|}
\hline & \multicolumn{7}{|l|}{ Postos Pluviométricos } & & \\
\hline Intervalos (mm) & P1 & P2 & P3 & P4 & FA/ FR & Representação \\
& & & & & & \\
\hline $99,4-227,9$ & 14 & 3 & 6 & 3 & $26 / 8,5 \%$ & Seco \\
\hline $228-356,5$ & 20 & 19 & 24 & 26 & $89 / 29,8 \%$ & Habitual \\
\hline $356,6-485,1$ & 19 & 19 & 18 & 22 & $78 / 25,6 \%$ & Habitual \\
\hline $485,2-613,7$ & 15 & 18 & 18 & 13 & $64 / 21 \%$ & Habitual \\
\hline $613,8-742,3$ & 5 & 12 & 6 & 7 & $30 / 9,9 \%$ & Chuvoso \\
\hline $742,4-870,9$ & 1 & - & 2 & 2 & $5 / 1,6 \%$ & Chuvoso \\
\hline $871-999,5$ & 2 & 1 & 2 & 2 & $7 / 2,3 \%$ & Chuvoso \\
\hline $999,6-1128,1$ & - & 3 & - & - & $3 / 0,98 \%$ & Muito Chuvoso \\
\hline $1128,2-1256,7$ & - & 1 & - & 1 & $2 / 0,65 \%$ & Muito Chuvoso \\
\hline Estações do Ano & 76 & 76 & 76 & 76 & $304 / 100 \%$ & \\
\hline P1 - São Borja; P2 - São Luiz Gonzaga; P3 - Santa Rosa; P4 - ljuí; FA - Frequência Absoluta FR - Frequência relativa \\
\hline
\end{tabular}

Nesta análise os acumulados variaram de 99,4 a 1256,7 mm, ou seja, verifica-se verões chuvosos, assim como secos, invernos chuvosos e mais secos, 
não se definindo estação seca ou chuvosa como visto na Figura 4, na qual a leitura deve ser feita de baixo para cima, respeitando a ordem sequencial das estações do ano e a ordem cronológica do estudo que vai desde 1992 a 2011.

O ano de 2004 foi o menos chuvoso; observa-se que do verão à primavera os índices de chuva foram mínimos para o período nas quatro localidades. São Luiz Gonzaga registrou o mínimo de chuva no verão de 2004. Não se pode afirmar que determinada estação do ano seja a mais suscetível a ocorrerem estiagens, pois se verificou os menores valores de chuva tanto no verão como no inverno e outono.

Neste raciocínio foram analisados os períodos chuvosos dos anos de 1997 e 1998, sendo da primavera de 1997 para o verão de 1998 o período em que ocorreram os valores mais elevados de chuva em São Luiz Gonzaga. Com isso mostra-se que os máximos de chuva ocorreram na primavera e verão, e os mínimos ou valores abaixo do habitual ocorreram de forma variável ao longo do ano. Desta forma, a primavera apareceu como o período em que os volumes foram mais significativos.

Independente da época do ano, nos anos menos chuvosos o setor oeste da região foi aquele que registrou acumulados inferiores, comprovando a tendência de que, quando se configura um período menos chuvoso, quanto mais a oeste menores são os índices de chuva, exemplo o verão de 2004. Nos períodos mais chuvosos a área central (São Luiz Gonzaga) apresenta geralmente os acumulados mais elevados exemplos, do inverno de 1992 ao outono de 1993, da primavera de 1995 ao verão de 1996, do inverno de 1997 ao verão de 1998 e primavera de 2009 ao verão de 2010 . 


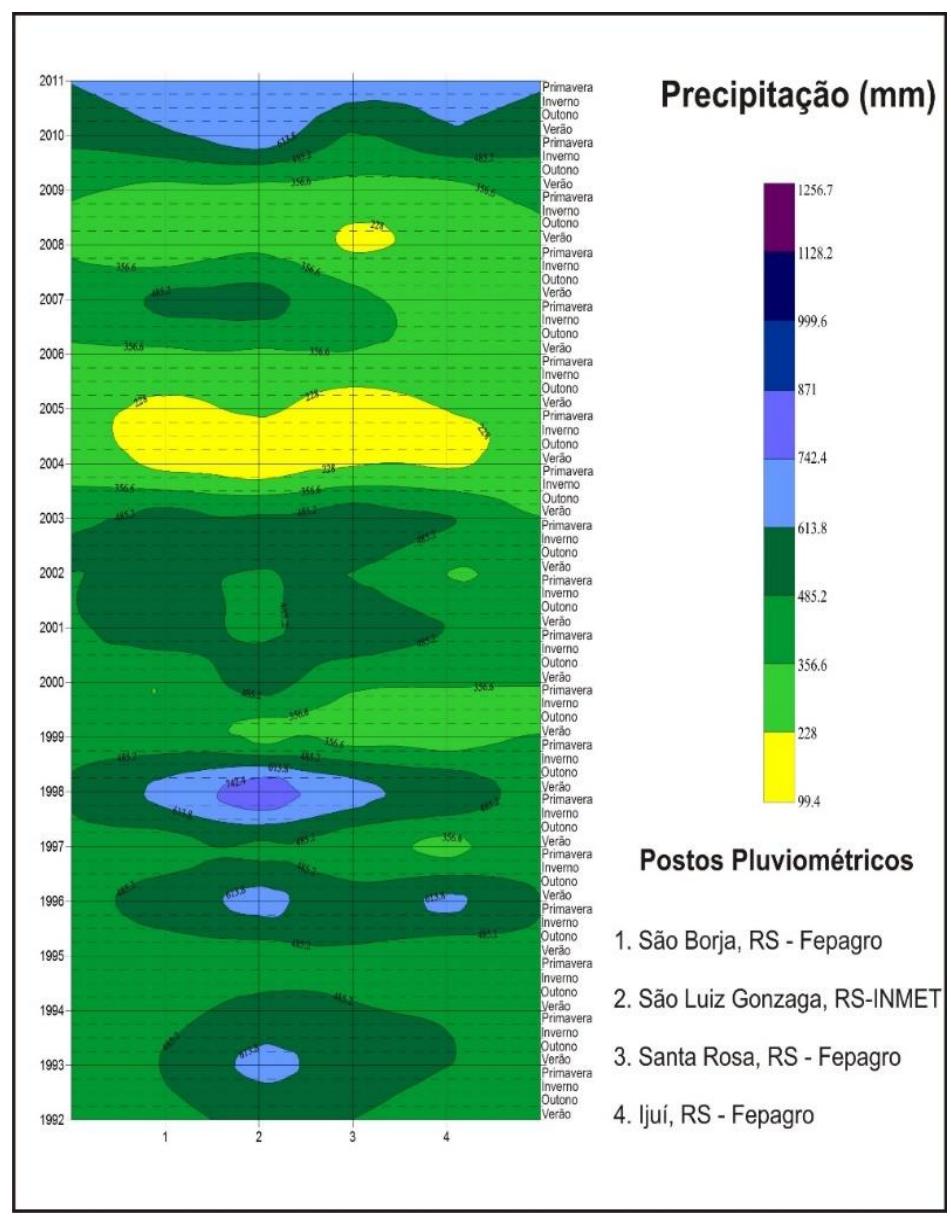

Figura 4 - Painel têmporo espacial sazonal das chuvas na região Missões Período 19922010.Organização: RIBEIRO, A. de. A. 2016.

\subsection{DISTRIBUIÇÃO TÊMPORO ESPACIAL DA PRECIPITAÇÃO MENSAL}

A análise da variação das chuvas é complementada pela análise mensal. Verificou-se meses em determinados anos com valores acumulados baixos, (inferiores a 62,6 mm), e alguns elevados pontuais que ultrapassaram $313 \mathrm{~mm}$. A partir da análise de frequência e dos intervalos de classes definidos segundo Sturges, (Quadro 3) o volume normal mensal nas Missões ficou entre 62,6 e $250,4 \mathrm{~mm}$.

Os anos que apresentaram o maior número de meses com acumulado de chuva inferior a 62,6 mm foram 1992, 1998, 1999, 2000, 2004 e 2008 (Figura $5)$. Nestes seis anos, ao menos um mês esteve com precipitação acumulada abaixo do esperado, ou seja, o posto 4 de Ijuí foi o que menos registrou os índices pequenos. As demais localidades situadas, a oeste de Ijuí, ao menos em um ano registraram mais de um mês com acumulado abaixo do habitual. Este resultado revela, que no leste das Missões os acumulados de chuva anuais, sazonais e mensais são maiores que os das localidades situadas ao centro, a norte e a oeste da Região. 
Quadro 3 - Frequência de distribuição do volume de chuva mensal conforme Sturges para definição de classes representativas de menos chuvoso, habitual e mais chuvoso para a área de estudo entre os anos de 1992 a 2010. Organização: RIBEIRO, A. de. A. 2016

\section{Postos Pluviométricos}

\begin{tabular}{|c|c|c|c|c|c|c|}
\hline Intervalos (mm) & P1 & $\mathbf{P 2}$ & P3 & P4 & FA/ FR & Representação \\
\hline $0-62,6$ & 49 & 29 & 39 & 30 & $147 / 16,1 \%$ & $\sec 0$ \\
\hline $62,7-125,3$ & 70 & 65 & 69 & 75 & $279 / 30,5 \%$ & Habitual \\
\hline $125,4-188$ & 53 & 59 & 58 & 56 & $226 / 24,8 \%$ & $\overline{\text { Habitual }}$ \\
\hline $188,1-250,7$ & 29 & 41 & 32 & 42 & $144 / 15,8 \%$ & Habitual \\
\hline $250,8-313,4$ & 17 & 19 & 22 & 14 & $72 / 7,9 \%$ & Chuvoso \\
\hline $313,5-376,1$ & 4 & 11 & 4 & 2 & $21 / 2,3 \%$ & $\overline{\text { Chuvoso }}$ \\
\hline $376,2-438,8$ & - & 5 & 2 & 5 & $12 / 1,3 \%$ & Chuvoso \\
\hline $438,9-501,5$ & 3 & 1 & 1 & 1 & $6 / 0,65 \%$ & Muito Chuvoso \\
\hline $501,6-564,2$ & 2 & 1 & - & 1 & $4 / 0,43 \%$ & Muito Chuvoso \\
\hline $564,3-626,9$ & - & - & 1 & - & $1 / 0,10 \%$ & Muito Chuvoso \\
\hline $627-689,6$ & - & 2 & - & 1 & $3 / 0,32 \%$ & Muito Chuvoso \\
\hline Meses & 228 & 228 & 228 & 228 & $912 / 100 \%$ & \\
\hline
\end{tabular}

Os anos que apresentaram o maior número de meses com acumulado de chuva inferior a 62,6 mm foram 1992, 1998, 1999, 2000, 2004 e 2008. Nestes seis anos, ao menos um mês esteve com precipitação acumulada abaixo do esperado, ou seja, o posto 4 de Ijuí foi o que menos registrou os índices inferiores. As demais localidades situadas, a oeste de Ijuí, ao menos em um ano registraram mais de um mês com acumulado abaixo do habitual. Este resultado revela, que no leste das Missões os acumulados de chuva anuais, sazonais e mensais são maiores que os das localidades situadas ao centro, a norte e a oeste da região.

No período os meses que registraram valores acima do habitual para a região foram pouco frequentes. Os anos de 1996, 2009 e 2010 foram os únicos que tiveram, no mínimo, um mês que ultrapassou $250 \mathrm{~mm}$. Na Figura 5 constata-se que em 2009 e 2010 São Borja e São Luiz registraram os maiores volumes, o que confirma também o fato de a área central da região, representada por São Luiz Gonzaga, bem como o oeste, representada por São Borja, serem onde ocorrem os valores de chuvas mais elevados em anos mais chuvosos e mais baixos nos anos menos chuvosos. 


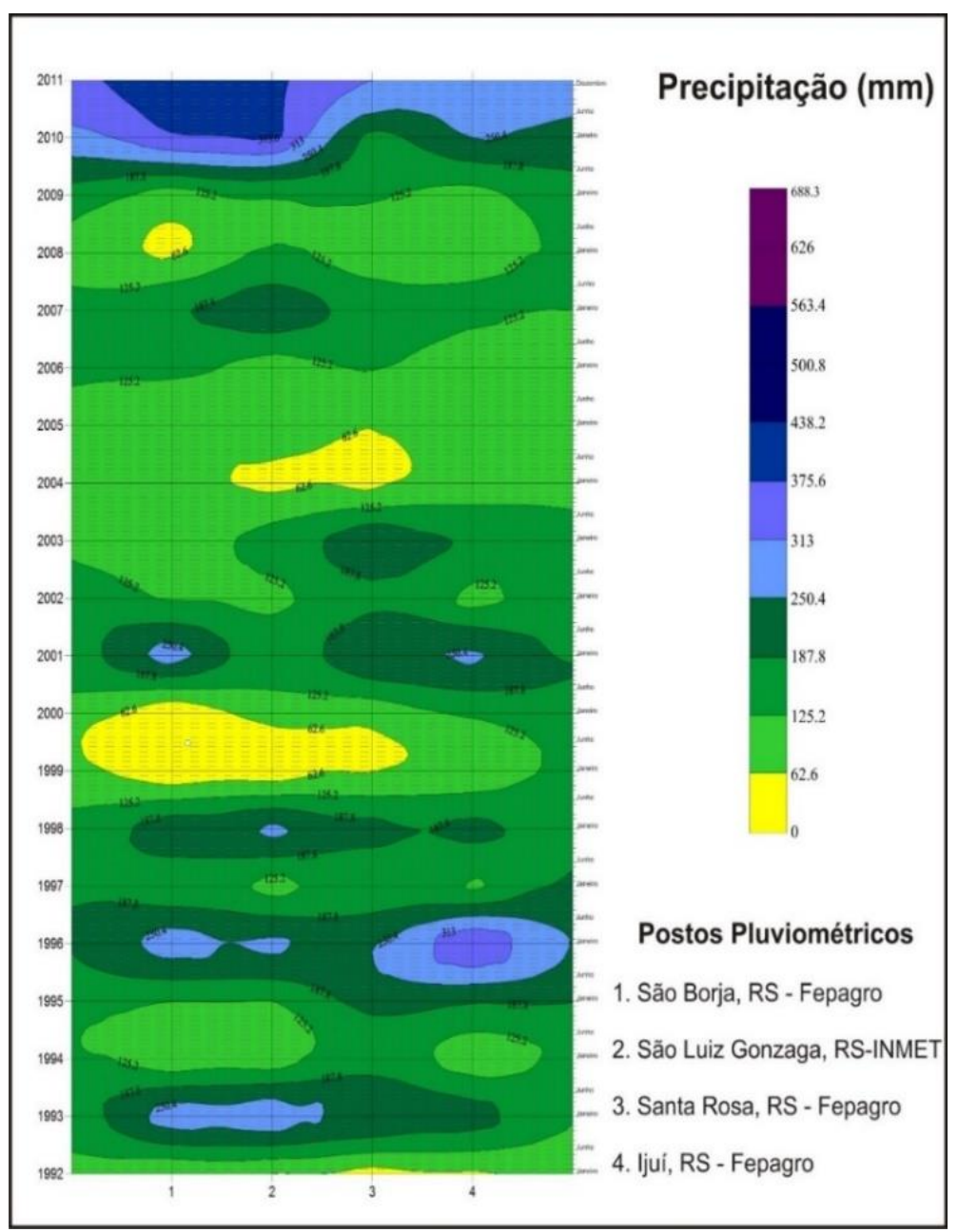

Figura 5 - Painel têmporo espacial mensal das chuvas na região Missões Período 19922010.Organização: RIBEIRO, A. de. A. 2016.

\subsection{REGIME DAS CHUVAS NA ÁREA DE ESTUdO}

$\mathrm{Na}$ análise sazonal da distribuição das chuvas constatou-se ser o período de maior precipitação no Estado aquele que vai de meados do outono a meados de primavera pelo fato de ser esta a época de maior atividade frontal pela intensificação das massas polares e tropicais no sul do País. Neste intuito, foi feita a análise porcentual mensal das chuvas para o período com base nos pluviogramas de Schröder (1956), os quais compõem as Figuras 6 a 9 das localidades de São Borja, São Luiz Gonzaga, Santa Rosa e Ijuí, respectivamente. Assim, buscou-se comprovar serem estes ou outros os meses em que se concentra o maior ou menor volume de chuva para a Região, bem como constatar quais os meses que tem maior participação nos volumes máximos e mínimos de chuva.

A Figura 6, pluviograma de São Borja, mostra, assim como na análise dos painéis têmporo espaciais, que os anos de 1995 e 2004 foram de fato os menos chuvosos do período, quando o acumulado mínimo de chuva foi de apenas 989,3 mm em 2004, assim como 1998, 2000, 2002 e 2010 os anos mais 
chuvosos, sendo que o máximo acumulado em 2002 atingiu 2555,4mm. Já Figura 7, pluviograma de São Luiz Gonzaga, também expressa os anos de 1995 e 2004 como menos chuvosos, neste último alcançando apenas 1122,0 mm.

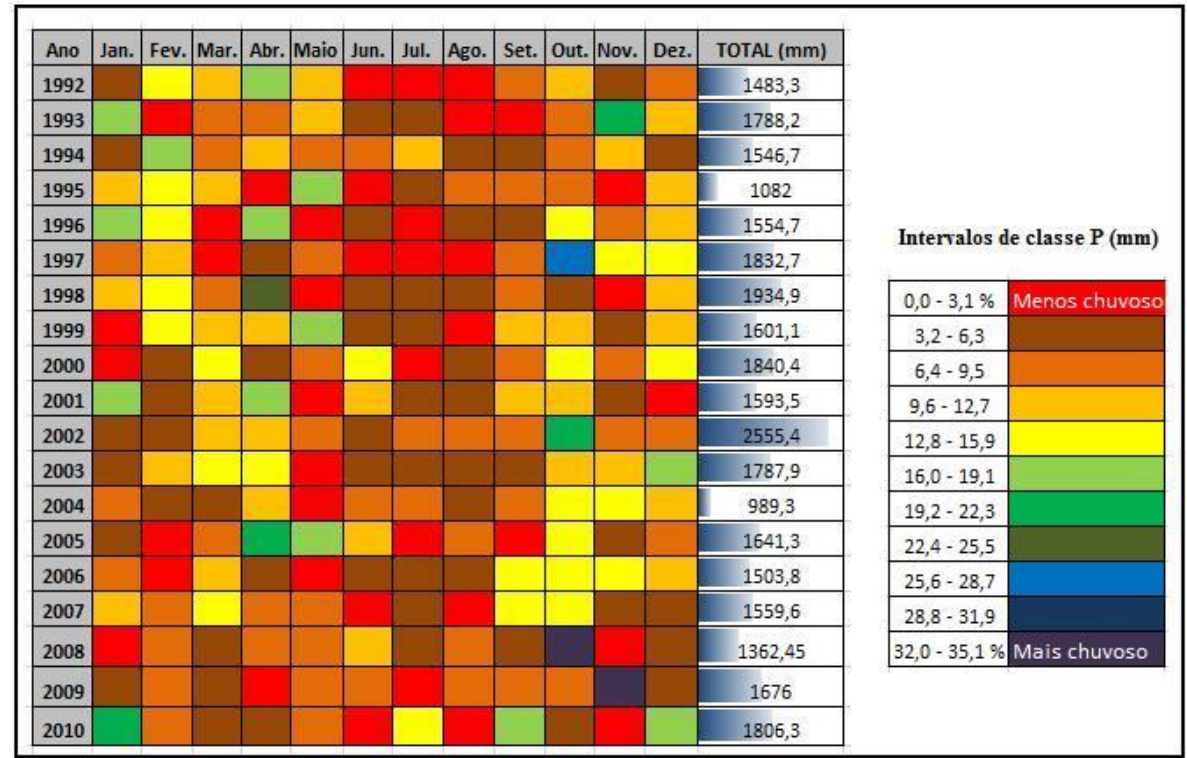

Figura 6 - Pluviograma (1) São Borja, RS, conforme Schröder (1956) - Período 19922010. Fonte: BDMET/INMET e FEPAGRO. Organização: RIBEIRO, A. de. A. 2016.

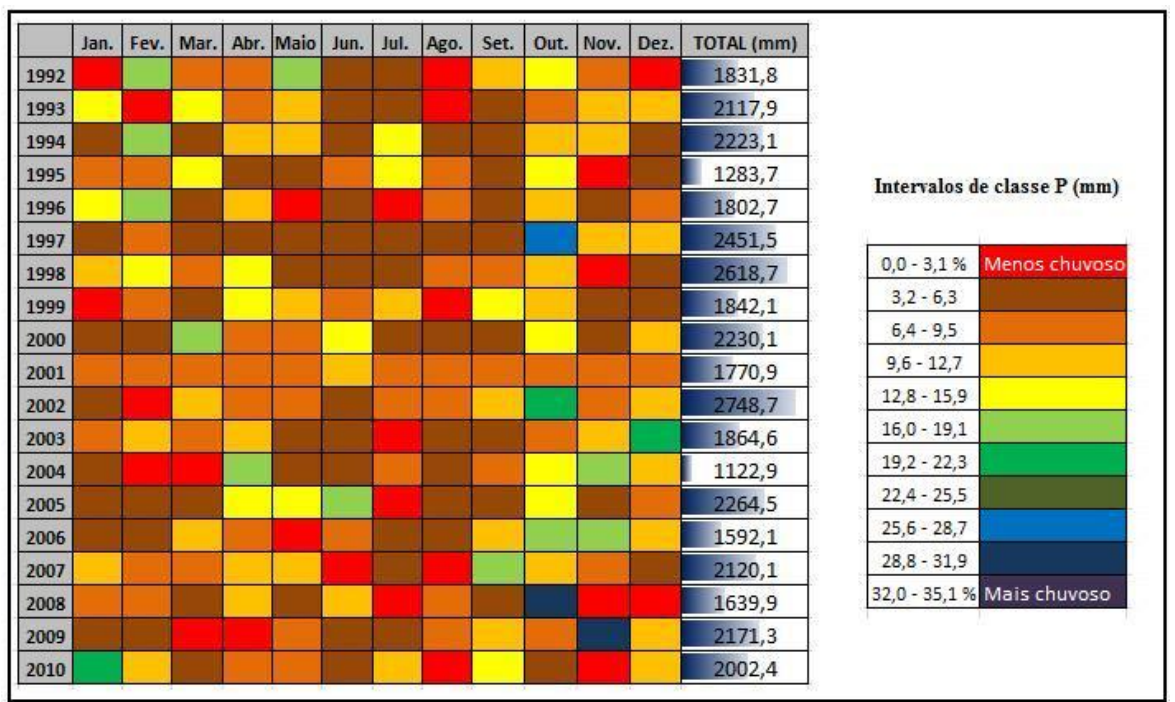

Figura 7 - Pluviograma (2) São Luiz Gonzaga, RS conforme Schröder (1956) - Período 1992-2010. Fonte: BDMET/INMET e FEPAGRO. Organização: RIBEIRO, A. de. A. 2016.

Para São Borja e São Luiz Gonzaga (Figura 6 e 7) as frequências de distribuição das chuvas ao longo dos meses do ano revelaram 3,2 a 12,7 \% são os índices porcentuais que compreendem os intervalos de classe em que se enquadra a precipitação esperada para cada mês, ou seja, o representativo do habitual e que está compreendido nas classes de cores do marrom escuro, passando pelo marrom até o amarelo-escuro, conforme visto nas Figuras. 
Ao se comparar os pluviogramas das Figura 6 e 7 na análise de frequência dos índices porcentuais da participação de cada mês na precipitação total anual, percebe-se que em São Borja há maior frequência de meses com participação abaixo do esperado, ou seja, com participação que varia de 0,0 a $3,1 \%$, sinalizado pela cor vermelha, em relação a São Luiz Gonzaga, onde a frequência de participação é menor. Ou seja, os meses menos chuvosos são mais presentes em São Borja do que em São Luiz Gonzaga, o que significa que em períodos pouco chuvosos quanto mais a oeste da região missioneira, maior é a falta de chuva, maior a suscetibilidade à estiagens, pois São Borja, por exemplo, no ano de 2004 obteve o índice anual mais baixo de chuva entre as demais localidades, que foi de $989,3 \mathrm{~mm}$.

Conforme o pluviograma da Figura 6, São Borja, o único mês que não figurou em nenhum ano com índice mínimo de participação foi outubro, mês que corresponde à primavera período que mais chove na região conforme as análises dos painéis têmporo espaciais sazonais e mensais. Os índices máximos de participação das chuvas também se concentraram em São Borja nos meses de outubro de 1997 e 2008 e em novembro de 2009.

No pluviograma da Figura 7, de São Luiz Gonzaga, dois meses não apresentaram em nenhum ano o índice mínimo de participação, setembro e outubro, ou seja, ao longo dos 19 anos foram os menos suscetíveis às estiagens, pois não se enquadraram na classe de menos chuvoso. Os índices máximos de participação das chuvas também se concentraram, em São Luiz Gonzaga, nos meses de outubro e novembro nos anos de 2008 e 2009, respectivamente.

A distribuição do volume de chuva entre os meses do ano, assim como para as estações do ano, são variáveis. Ao se observar tanto os pluviogramas das Figuras 6 e 7 como os das Figuras 8 e 9, que serão analisados a seguir, não há condição de se separar meses chuvosos ou menos chuvosos. Isso se deve a característica das chuvas, no Estado, serem "bem distribuídas" o ano todo, ou seja, os períodos de estiagens e de chuva dificilmente se concentram em meses ou estações do ano pré-fixadas, por este fato, ao se analisar os pluviogramas não se consegue estabelecer um padrão da participação dos meses na precipitação anual, percebendo-se padrão difuso e variado ao longo dos anos.

A Figura 8, pluviograma de Santa Rosa, mostra, assim como na análise dos painéis têmporo espacias e nos pluviogramas anteriores, que os anos de 1995 e 2004 se confirmam entre os menos chuvosos do período com acumulado mínimo de chuva de 1141,8 mm, em 2004; da mesma forma 1998, 2002, 2009 e 2010 destacaram-se como os anos mais chuvosos, sendo o máximo acumulado em 2002, quando atingiu 2460,2 mm. Já na Figura 9, pluviograma de Ijuí também se constata os anos de 1995 e 2004 como os menos chuvosos, com totais que alcançaram apenas 1163,3 mm em 2004.

Para Santa Rosa e Ijuí (Figuras 8 e 9), as frequências de distribuição das chuvas ao longo dos meses do ano revelaram que de 3,2 a $15,9 \%$ são os índices porcentuais esperados para cada mês, ou seja, o representativo do habitual conforme visto nas Figuras. 


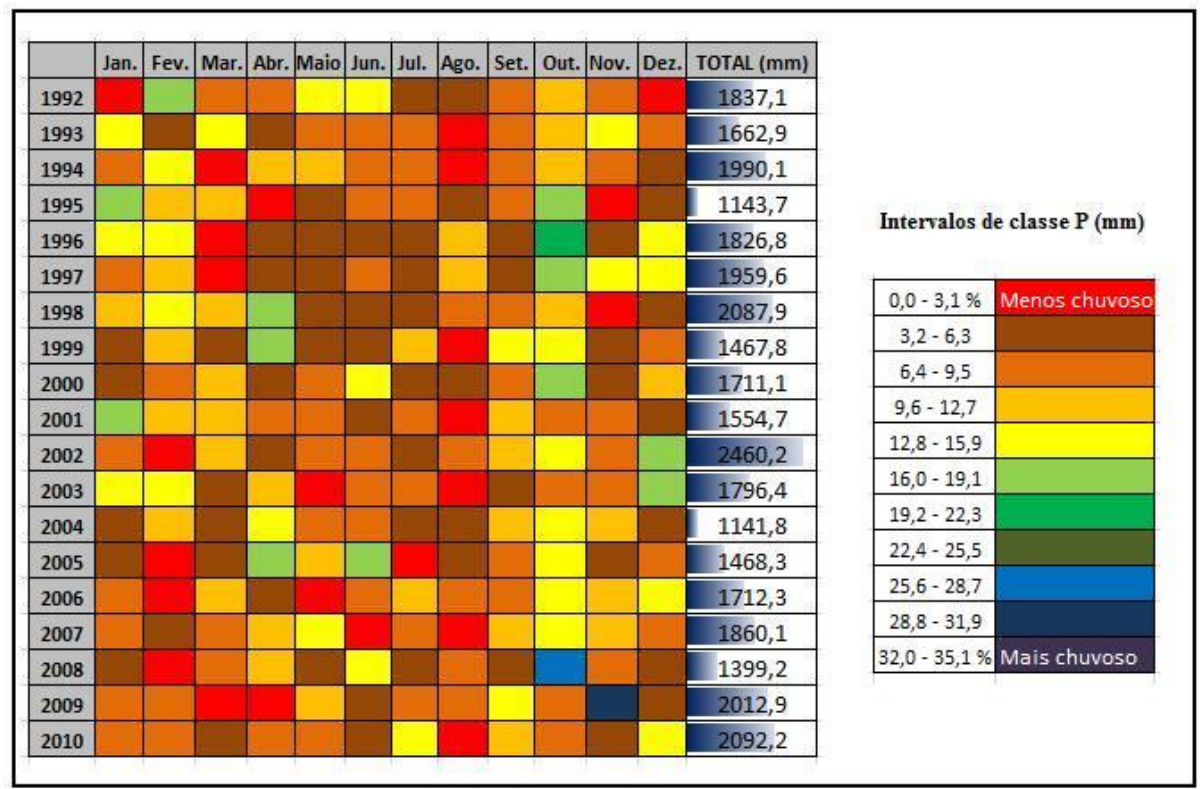

Figura 8 - Pluviograma (3) Santa Rosa, RS conforme Schröder (1956) - Período 19922010. Fonte: BDMET/INMET e FEPAGRO. Organização: RIBEIRO, A. de. A. 2016.

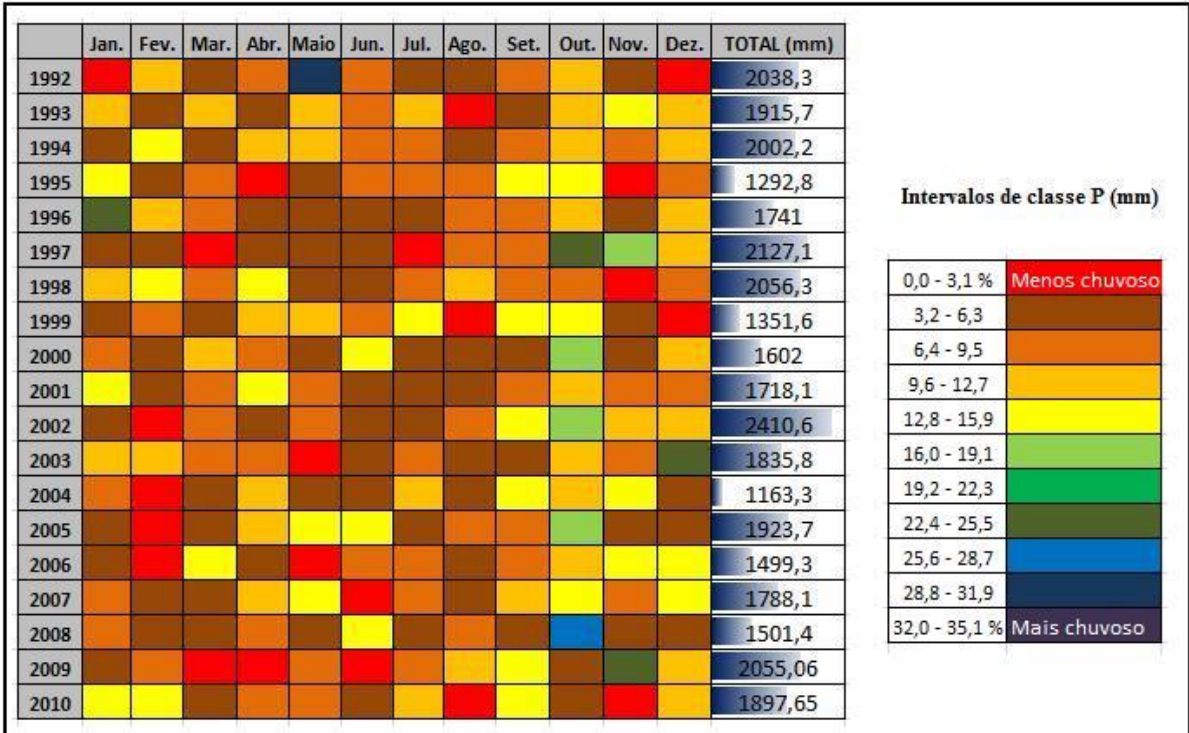

Figura 9 - Pluviograma (4) Ijuí, RS conforme Schröder (1956) - Período 1992-2010. Fonte: BDMET/INMET e FEPAGRO. Organização: RIBEIRO, A. de. A. 2016.

Ao se comparar os pluviogramas das Figuras 8 e 9 mediante a análise de frequência dos índices porcentuais da participação de cada mês na precipitação total anual, percebe-se que em Santa Rosa há maior frequência de meses com participação abaixo do esperado $(0,0 \%$ a 3,1\%), sinalizado pela cor vermelha, em relação a Ijuí, onde a frequência de participação é menor quando se compara os índices abaixo do habitual. 
Os meses menos chuvosos são mais frequentes em Santa Rosa do que em Ijuí, o que significa que em períodos pouco chuvosos quanto mais a oeste da região, maior é a falta de chuva, ou seja, é maior a suscetibilidade à estiagens. Além disso, comparando Santa Rosa e Ijuí com São Luiz e São Borja, a frequência de meses com participação na precipitação anual abaixo do normal é maior de leste para oeste, ou seja, 22 em Ijuí, 25 em Santa Rosa, 26 em São Luiz Gonzaga e 40 em São Borja o que significa maior frequência de meses com participação abaixo do habitual em São Luiz Gonzaga (centro da região) e São Borja (a oeste).

A partir do pluviograma da Figura 8, de Santa Rosa, os meses que não figuraram em nenhum ano com índice mínimo de participação foram setembro e outubro, que correspondem ao final do inverno e início da primavera, período já definido como o que mais chove, conforme os painéis têmporo espaciais. Os índices máximos de participação das chuvas se concentraram, em Santa Rosa, no mês de outubro de 2008 e em novembro de 2009.

No pluviograma da Figura 9, de Ijuí, dois meses não apresentaram em nenhum ano índice mínimo de participação (setembro e outubro), ou seja, foram os menos suscetíveis às estiagens, pois não enquadraram-se na classe de menos chuvoso. Os índices máximos de participação das chuvas se concentraram, em Ijuí, em maio e outubro de 1992 e 2008, respectivamente.

\section{CONCLUSÕES}

Constatou-se, com a análise da chuva que a Região das Missões apresenta variação significativa do volume da chuva, tanto se destacando nos anos secos como nos chuvosos perante o entorno. As Missões, constitui-se como área atingida por grande variação no regime e distribuição da precipitação, e que, independente da época do ano, nos anos menos chuvosos o setor oeste da região foi aquele que registrou acumulados menores, comprovando a tendência de que, quando se configura um período de estiagem, quanto mais a oeste maiores são as ocorrências de estiagens e o exemplo disso é o do verão de 2004.

Já nos períodos chuvosos a área central da região, São Luiz Gonzaga, apresenta os maiores volumes, a exemplo do inverno de 1997 ao verão de 1998 e primavera de 2009 ao verão de 2010. São Luiz Gonzaga situa-se no centro da região, e ao se observar os valores de chuva registrados para esta localidade, comprova-se que o cerne das Missões sofre ciclicamente variações significativas no volume chuva havendo anos com estiagens, e anos com excesso de chuva. Assim, se apresenta tanto como referência para os mínimos acumulados em anos menos chuvosos, quanto como referência dos totais anuais máximos em anos chuvosos.

Os máximos de chuva nos 19 anos ocorreram na primavera e verão, e os valores abaixo do habitual se concentraram de forma variável ao longo do ano. Foi no verão que se teve a concentração das chuvas e estiagens, mas não se pode estabelecer que o verão é mais seco ou mais chuvoso. A primavera apareceu como o período em que os máximos acumulados de chuva foram bastante significativos. 
Desta forma, observa-se que um ano chuvoso não é necessariamente marcado por precipitações elevadas, e anos considerados não chuvosos podem ter períodos de excessos de chuva. Por isso é necessário uma análise em diferentes escalas de observação partindo-se de dados anuais, passando pelos sazonais e mensais até culminar em uma observação diária.

\section{AGRADECIMENTOS}

- À FAPESP - Fundação de Amparo à Pesquisa do Estado de São Paulo, Bolsa de Mestrado 2010 - 2012.

- Ao CNPq - Conselho Nacional de Desenvolvimento Científico e Tecnológico, Bolsa Doutorado 2015 - 2019.

- À Professora Dra. Maria da Graça Barros Sartori - in Memorian;

\section{REFERÊNCIAS BIBLIOGRÁFICAS}

BRITTO, F. P. BARLETTA, R. MENDONÇA, M. Regionalização sazonal e mensal da precipitação pluvial máxima no estado do Rio Grande do Sul. Revista Brasileira de Climatologia. Associação Brasileira de Climatologia. Ano 2. p. 35 - 51, 2006

FEPAGRO. Fundação Estadual de Pesquisa Agropecuária. Dados Meteorológicos de Precipitação (mm) Estações de São Borja, Santa Rosa e Ijuí 1992 - 2010. Porto Alegre, 2011

GERADI, L. H. de. O.; SILVA, B. C. Quantificação em geografia. São Paulo: DIFEL, 1981.

INMET. Dados Mensais de Precipitação $(\mathrm{mm})$ Estação Meteorológica São Luiz Gonzaga 1992 - 2010.Instituto Nacional de Meteorologia. Brasília, DF, 2011.

MONTEIRO, C. A. F. Análise Rítmica em climatologia: problemas da atualidade climática em São Paulo e achegas para um programa de trabalho. São Paulo, Instituto de Geografia da USP, 1971, n. 21. Série Climatologia, 1.

RIBEIRO, A. de. A. Eventos Pluviais Extremos e Estiagens na Região das Missões, RS: a Percepção dos Moradores do Município de Santo Antônio das Missões.2012. Dissertação Mestrado. Programa de Pós-Graduação em Geografia, Organização do Espaço. Universidade Estadual Paulista. Rio Claro, 2012.

SCHRÖDER, R. Distribuição e curso anual das precipitações no estado de São Paulo. Bragantina: Boletim Técnico do Instituto Agronômico do Estado de São Paulo. n. 18, v.5, Campinas, 1956.

SORRE, M. Les Fondaments de La Géographie Humaine. Tome: 1 Les Fondaments biologiques. Essai d'une écologie de l'homme. Paris: Librairie Armand Colin, 1951.

ZAVATTINI, J. A. Estudos do Clima no Brasil. Campinas: Alínea, 2004 